(c) American Dairy Science Association, 2003.

\title{
Production of Free Conjugated Linoleic Acid by Lactobacillus acidophilus and Lactobacillus casei of Human Intestinal Origin ${ }^{1}$
}

\author{
L. Alonso, ${ }^{2}$ E. P. Cuesta, and S. E. Gilliland \\ Department of Animal Science and \\ Food and Agricultural Product Research and Technology Center \\ Oklahoma State University \\ Stillwater 74078
}

\begin{abstract}
A gas chromatographic procedure was used for analysis of conjugated linoleic acid (CLA) isomers cis-9, trans11-octadecadienoic; trans-10, cis-12 octadecadienoic; and trans-9, trans-11-octadecadienoic (c9t11, t10c12, t9t11) produced by lactobacilli. Four different cultures, two strains each of Lactobacillus acidophilus and Lactobacillus casei were tested for their ability to produce CLA from free linoleic acid in MRS broth supplemented with linoleic acid. Different concentrations of linoleic acid $(0,0.05,0.1,0.2$ and $0.5 \mathrm{mg} / \mathrm{ml})$ were added to MRS broth, inoculated with the lactobacilli, and incubated at $37^{\circ} \mathrm{C}$. Viable counts and amounts of individual isomers of CLA (c9t11, t10c12, t9t11) were measured at $0,24,48$, and $72 \mathrm{~h}$. All the cultures were able to produce free CLA in media supplemented with linoleic acid. Maximum production of CLA (80.14 to $131.63 \mu \mathrm{g} / \mathrm{ml}$ ) was observed at $24 \mathrm{~h}$ of incubation in broth containing $0.02 \%$ of free linoleic acid. No significant $(P>0.05)$ increases in total CLA levels were observed after $24 \mathrm{~h}$ of incubation. The ability of the cultures to produce CLA in skim milk supplemented with $0.02 \%$ free linoleic acid also was studied. In this medium, the total amounts of free CLA after $24 \mathrm{~h}$ of incubation ranged from 54.31 to $116.53 \mu \mathrm{g} / \mathrm{ml}$. The use of lactic acid bacteria able to form free CLA in cultured dairy products may have potential health or nutritional benefits. Free CLA in the products likely would be more readily available for absorption from the digestive tract than if it were incorporated into the cells of the starter culture.
\end{abstract}

(Key words: conjugated linoleic acid, gas liquid chromatography, lactobacillus, probiotics)

Received July 30, 2002.

Accepted November 5, 2002.

Corresponding author: S. E. Gilliland; e-mail: seg@okstate.edu.

${ }^{1}$ Approved for publication by the Director, Oklahoma Agricultural Experiment Station. This project was supported under Project H2293 and Sitlington Endowment Funds.

${ }^{2}$ Present address: Instituto de Productos Lacteos de Asturias (CSIC). Carretera de Infiesto, s/n. Apdo. 85, 33300 Villaviciosa, Asturias, Spain.

\begin{abstract}
Abbreviation key: CLA = conjugated linoleic acid, c9,t-11 = cis-9, trans-11, FAME = fatty acid methyl ester, $\mathbf{N F M}=$ nonfat milk, $\mathbf{S M}=$ skim milk, t-10,c12 = trans 10,cis-12, t9,t11 = trans -9, trans -11 .
\end{abstract}

\section{INTRODUCTION}

Conjugated linoleic acid (CLA) is a generic name for a mixture of isomers of linoleic acid with conjugated double bonds. The double bonds can be in several possible positions either as cis or trans isomers. Double bonds of CLA are mainly found at positions 9 and 11, or 10 and 12 (Ha et al., 1987), while isomers having double bonds at other positions also have been reported (Christie et al., 1997). Several scientists, based on studies primarily in animal models, have suggested that CLA has potential health or nutritional effects, including anticarcenogenic activity (Ha et al., 1990), antiatherogenic activity (Lee et al., 1994; Pariza et al.,1996), the ability to reduce the catabolic effects of immune stimulation (Cook et al., 1993), and the ability to reduce body fat (Pariza et al., 1996). Of the individual isomers of CLA, cis-9, trans-11-octadecadienoic acid has been implicated as the most biologically active because it is the predominant isomer incorporated into the phospholipids of cell membranes (Ip et al., 1994). The cis-9, trans-11 CLA isomer also is the predominant isomer found in the diet.

Food products from ruminants, particularly dairy products, are the major dietary source of CLA for humans. They are intermediates in the biohydrogenation of linoleic acid, and it is generally accepted that CLA in ruminants originate from the incomplete biohydrogenation of the unsaturated fatty acid linoleic acid by rumen bacteria (Kelly et al., 1998). However, it has been demonstrated that cows also can synthesize CLA from trans-11-octadecenoic acid, another intermediate in the rumen biohydrogenation process (Kim and Liu, 2000).

Information is lacking on CLA levels required by humans, but it is estimated from animal studies that a 
daily intake of $3 \mathrm{~g} / \mathrm{d}$ may be effective for cancer prevention (Ip et al., 1994). The average estimated CLA intake has been reported to range from 0.35 to $1 \mathrm{~g} / \mathrm{d}$ (Chin et al., 1992; Fritsche et al., 1998). Dietary sources of CLA include milk fat, natural and processed cheeses, meat products, and plant oil (Ha et al., 1989; Shanta et al., 1992). Animal sources are richer in CLA than plant sources, and in general, foods from ruminants contain more CLA than foods from non ruminants. Considerable research has been conducted on the CLA content and isomer distribution in cow's milk. A number of factors have been shown to influence CLA concentration in bovine milk fat, including stage of lactation (Stanton et al., 1997), dietary restriction (Ip et al., 1991), and feed allowance (Stanton et al., 1997; Lawless et al., 1998). Among the different isomers of CLA, cis-9, trans11-octadecadienoic represents more than $90 \%$ of the total CLA in milk fat. The level of CLA in raw milk fat varies from 0.2 to $2 \%$ (wt/wt). The wide variation of CLA content in dairy products also may be due to processing parameters such as different heat treatment procedures during pasteurization. The CLA content in yogurt or cheese can be increased by action of the starter cultures (Lin et al., 1999). The finding of the production of CLA by food starter cultures opens interesting perspectives for the future in producing fermented products enriched in CLA.

Jiang et al. (1998) reported the formation of CLA from linoleic acid by Propionibacterium freudenreichii. Their study also included seven cultures of lactobacilli, none of which were found to form CLA. Lin et al. (1999), Lin (2000), and Ogawa et al. (2001) reported the production of CLA from free linoleic acid by Lactobacillus acidophilus. Each study included one strain, and in all cases the entire culture (i.e., growth medium plus cells) was assayed for CLA. Kishino et al. (2002) found that washed cells of Lactobacillus plantarum formed high levels of CLA from free linoleic acid upon extended incubation. They indicated most of the CLA for this culture was associated with the bacterial cells.

The objective of this study was to evaluate the capacity of $L$. acidophilus and $L$. casei of human intestinal origin to produce free CLA in MRS broth and in skim milk.

\section{MATERIALS AND METHODS}

\section{Cultures, Media, and Growth Conditions}

Two strains of L. acidophilus (L1 and O16) and two of $L$. casei (E5 and E10) isolated from human intestinal sources were used in this study (Buck and Gilliland, 1994; Brashears et al., 1998). The strains were obtained from the stock culture collection of the Food Microbiology Laboratory at the Food and Agricultural Product
Research and Technology Center, Oklahoma State University. The cultures were subcultured at least three times in MRS broth or $10 \%$ nonfat milk (NFM) immediately before experimentation using $1 \%$ inocula and an 18 -h incubation at $37^{\circ} \mathrm{C}$. The cultures were held at $2^{\circ} \mathrm{C}$ between subcultures.

\section{Production of CLA in Broth}

Lactobacilli MRS broth (Difco Laboratories, Detroit, MI), supplemented with different concentrations of linoleic acid $(0,0.05,0.1,0.2$ and $0.5 \mathrm{mg} / \mathrm{ml})$, was used in this study. The linoleic acid (Sigma Chemical Co., St. Louis, MO) was added as aqueous solution in 1\% (vol/ vol) of Tween 80 . The broth medium was inoculated at $1 \%$ and incubated at $37^{\circ} \mathrm{C}$ for $0,24,48$, and $72 \mathrm{~h}$. After each incubation period, a tube of culture from each concentration of linoleic acid was placed in an ice-water bath. The $\mathrm{pH}$ was measured and viable count was determined by plating appropriate dilutions on MRS agar. (The plates were incubated $48 \mathrm{~h}$ at $37^{\circ} \mathrm{C}$.) Then samples were centrifuged at $23,500 \times g$ for $10 \mathrm{~min}$ at $5^{\circ} \mathrm{C}$. The pellet was discarded, and the supernatant was recovered for CLA analysis. The complete experiment, including all cultures, was replicated three times on different days.

\section{Production of CLA in Milk}

NFM was reconstituted at 10\% (wt/vol) in deionized water and supplemented with $0.2 \mathrm{mg} / \mathrm{ml}$ linoleic acid. The milk was pasteurized at $80^{\circ} \mathrm{C}$ for $30 \mathrm{~min}$ and then inoculated at $1 \%$ and incubated at $37^{\circ} \mathrm{C}$ for $24 \mathrm{~h}$. After incubation, viable count was determined by plating in MRS agar. Then samples were centrifuged at 23,500 $\times$ $g$ for $10 \mathrm{~min}$ at $5^{\circ} \mathrm{C}$. The pellet was discarded, and supernatant (whey) was kept for CLA analysis. The complete experiment involving all cultures was replicated three times on different days.

\section{Lipid Extraction}

Six milliliters of spent broth or whey was mixed with $60 \mu \mathrm{l}$ of heptadecanoic (Sigma Chemical Co., St. Louis, MO), which served as internal standard $(64.4 \mathrm{mg}$ of heptadecadienoic $/ 10 \mathrm{ml}$ of hexane), and $12 \mathrm{ml}$ of isopropanol and shaken vigorously; $9 \mathrm{ml}$ of hexane were then added, and the mixture was shaken 3 min before being centrifuged at $1900 \times g$ for $5 \mathrm{~min}$ at $5^{\circ} \mathrm{C}$. The upper layer was then collected by aspiration and filtered through sodium sulphate. After filtration, the sodium sulfate was washed with an additional $7 \mathrm{ml}$ of hexane. The lipid fraction of the sample was collected in a $25-\mathrm{ml}$, pear-shaped flask and dried under nitrogen gas at $70^{\circ} \mathrm{C}$ 


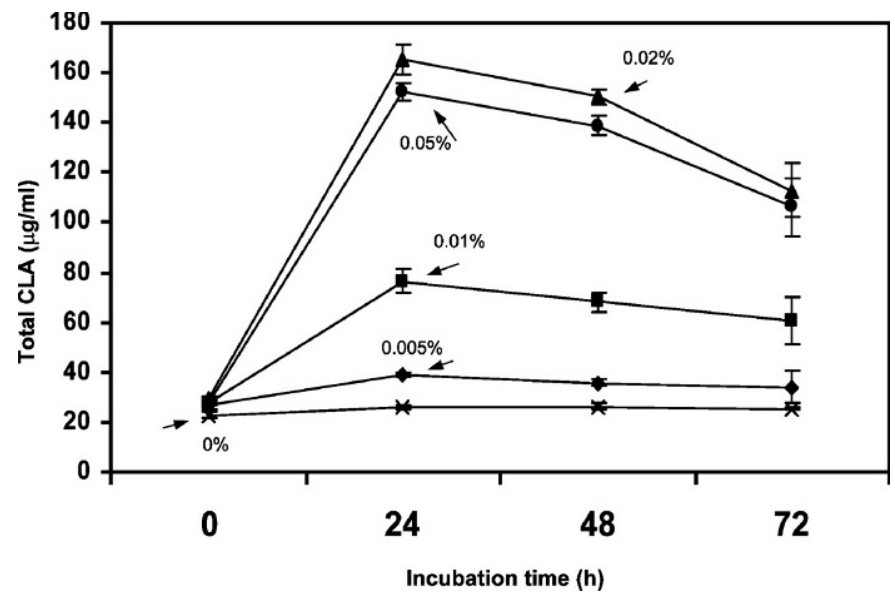

Figure 1. Production of total conjugated linoleic acid (CLA) by Lactobacillus acidophilus (L1) in MRS broth supplemented with 0\% $(\mathrm{x}), 0.005 \%(\diamond), 0.01 \%(\boldsymbol{\square}), 0.02 \%(\boldsymbol{\Delta})$ and $0.05 \%(\bullet)$ linoleic acid after $0,24,48$ and $72 \mathrm{~h}$ of incubation at $37^{\circ} \mathrm{C}$.

in a Zymark Turbo Vap LV evaporator (Zymark Corp., Hopkinton, MA). The dried sample was redisolved with $500 \mu \mathrm{l}$ hexane and transferred to a microtube. Methanolic sodium hydroxide $(1 N) 100 \mu \mathrm{l}$, was added to the tube containing the extracted lipid fraction, and the mixture was vortexed for $1 \mathrm{~min}$, then held at $70^{\circ} \mathrm{C}$ in a water bath for $15 \mathrm{~min}$. The free fatty acids in the mixture were methylated by adding $200 \mu \mathrm{l}$ of $14 \%$ boron trifluoride in methanol (Sigma Chemical Co. St. Louis, $\mathrm{MO}$ ) at room temperature for $30 \mathrm{~min}$. Then $0.2 \mathrm{ml}$ of hexane and $0.1 \mathrm{ml}$ of water were added, samples were vortexed thoroughly, and centrifuged at $200 \times g$ for 3 min. The organic layer was recovered and stored in a vial at $-20^{\circ} \mathrm{C}$ until being analyzed by GLC. Uninoculated broth or whey (collected from milk acidified to $\mathrm{pH}$ 4.5 with lactic acid) were extracted in a like manner to provide background levels of CLA isomers that might be present.

\section{Gas Chromatographic Analysis}

Methyl esters of CLA were analyzed as described by Alonso et al (2000). The specific equipment and materials included a Hewlett-Packard 5890 gas chromatograph equipped with a flame ionization detector. Analyses were performed with a CP Sil 88 column $(100 \mathrm{~m}$ $\times 0.25 \mathrm{~mm}$ i.d) containing $100 \%$ cyanopropyl siloxane stationary phase, $0.20-\mu \mathrm{m}$ film thickness (Chrompack, Varian, Inc., CA). The conditions used were $190^{\circ} \mathrm{C}$ isothermal temperature, $250^{\circ} \mathrm{C}$ injector temperature, and $250^{\circ} \mathrm{C}$ detector temperature. The split ratio was $1: 50$, and the carrier gas was helium with a head pressure of $28 \mathrm{psi}\left(1.97 \mathrm{~kg} / \mathrm{cm}^{2}\right)$. The injection volume was $1 \mu \mathrm{l}$, and the CLA peaks were identified by comparison with the retention times of the reference standards (Matreya, Inc., State College, PA). With the Millennium 32 Workstation SS (500) software (Waters Corp., Milford, MA), the amounts of CLA isomers in each sample were calculated ( $\mu \mathrm{g} \mathrm{CLA} / \mathrm{ml}$ ) based on the areas of individual CLA peaks.

\section{Statistical Analysis}

Data were subjected to analysis of variance for a onefactor completely randomized design and Duncan's multiple range tests (SAS User's Guide, 1995) procedure using a significance level of 0.05 . Concentration of linoleic acid and incubation time were the main effects studied.

\section{RESULTS AND DISCUSSION}

\section{Analyses of CLA}

The GLC technique using a long capillary column has been successful in quantitating total amount of CLA as FAME. This method separates with a good resolution, cis / trans and trans / trans isomers of CLA based on the chain length and number of double bonds. The advantages of methylating CLA are that the FAME derivatives allow for GLC identification and quantification of individual CLA isomers. The FAME, including the CLA, can be quantitated by GLC by adding an internal standard such as heptadecanoic acid (C17:0) into the lipid mixture before methylation (Yurawecz et al., 1996). The methylation procedure chosen will depend on the type and chemical composition of material to be methylated. In our study, we used a two-stage process for methylation, first an alkaline-catalyzed hydrolysis using $\mathrm{NaOH} /$ methanol for esterified CLA isomers, followed by boron trifluoride/methanol catalyzed methylation of the free CLA isomers. This method has an advantage over other methods for methylating CLA isomers in that it does not isomerize conjugated double bonds (Koritala and Rohwedder, 1972; Yurawecz, 1997). The retention times for the FAME of the three isomers of CLA (c9t11, t10c12, and t9t11) detected in this study were $43.9,45.1$, and $48.0 \mathrm{~min}$, respectively, which are indications of the separation obtained. Under conditions used in our study, this method produced a good repeatability as indicated by low coefficients of variation $(\mathrm{CV}=4.62$ to 8.20$)$. Sterile unsupplemented MRS broth contained 4 to $9 \mu \mathrm{g} / \mathrm{ml}$ of the three CLA isomers. Known amounts of the individual CLA isomers were added to MRS broth and assayed using heptadecanoic acid as internal standard. Recovery of CLA isomers was in the range of 87.22 to $89.57 \%$. The recovery values found in this study were slightly higher than those reported by Lin et al. (1999) using a KOH/ethanol and 
Table 1. Production of individual isomers and total conjugated linoleic acid (CLA) by Lactobacillus acidophilus and Lactobacillus casei ssp. casei in MRS broth supplemented with $0.02 \%$ of linoleic acid after $24 \mathrm{~h}$ of incubation at $37^{\circ} \mathrm{C}$.

\begin{tabular}{|c|c|c|c|c|c|c|}
\hline \multirow[b]{2}{*}{ Culture } & \multirow[b]{2}{*}{$\mathrm{pH}$} & \multirow[b]{2}{*}{$\log _{10} \mathrm{cfu} / \mathrm{ml}^{2}$} & \multicolumn{4}{|c|}{ Concentration $\mu \mathrm{g} / \mathrm{ml}^{1}$} \\
\hline & & & c9t11 & $\mathrm{t} 10 \mathrm{c} 12$ & t9t11 & Total CLA \\
\hline & 3.70 & 9.17 & 115.1 & $13.23 \pm 2.20$ & $7.3 \pm 0.56$ & $131.63 \pm 5.82^{\mathrm{a}}$ \\
\hline L. acidophilus $\mathrm{O}$ & 3.70 & $9.49 \pm 0.03$ & $54.77 \pm 0.04$ & $5.7 \pm 0.56$ & $0.39 \pm 0.06$ & $60.86 \pm 0.30^{b}$ \\
\hline L. casei E5 & 3.70 & $9.21 \pm 0.16$ & $93.9 \pm 2.25$ & $14.14 \pm 0.65$ & $3.14 \pm 0.76$ & $111.18 \pm 2.32^{\mathrm{c}}$ \\
\hline L. casei E10 & 3.70 & $9.51 \pm 0.06$ & $70.66 \pm 2.39$ & $7.03 \pm 0.45$ & $2.45 \pm 0.35$ & $80.14 \pm 2.31^{\mathrm{d}}$ \\
\hline
\end{tabular}

a,b,c,d Means in a column with different letter are significantly different $(P>0.05)$.

${ }^{1}$ Each value is a mean from three trials (the $\mu \mathrm{g} / \mathrm{ml}$ of each isomer was corrected for the small amounts present in uninoculated broth); values in parentheses are standard deviations.

${ }^{2} \log _{10}$ colony forming units per $\mathrm{ml}$ on MRS agar at end of incubation.

HCL as methylation reagent. They found $83 \%$ recovery of CLA and coefficient of variation $\mathrm{CV}=6.6$ for repeatability using a capillary GLC analysis. However, Jiang et al. (1996) reported the recovery of the CLA for the analytical procedure was $89.4 \%$, and the coefficient of variation for the overall reproducibility of the CLA quantification method was $3.6 \%$, using $\mathrm{KOH} /$ ethanol and HCL as reagent for methylation with HPLC-GLC analysis. Therefore, it was concluded that under the given conditions, the GLC method used in our study does not appreciably underestimate for individual CLA isomers (free plus esterified).

\section{CLA Production}

Two cultures each of Lactobacillus acidophilus (016, L1) and Lactobacillus casei (E5, E10) were able to convert free linoleic acid to CLA. Of the possible isomers of CLA, c9t11, t10c12, and t10t12 were formed, of which c9t11 comprised more than $90 \%$ of the total CLA. No significant increases $(P>0.05)$ in total amounts of CLA were formed for any of the four cultures as incubation time increased beyond $24 \mathrm{~h}$ in broth containing added linoleic acid. Figure 1 shows the production of total CLA by the L. acidophilus L1 in MRS broth supplemented with different amounts of free linoleic acid during 24, 48 , and $72 \mathrm{~h}$ of incubation time at $37^{\circ} \mathrm{C}$. The highest level of CLA production was observed after $24 \mathrm{~h}$ of incubation in the broth supplemented with $0.02 \%$ linoleic acid. Similar patterns of formation of CLA were obtained with the other cultures included in this study. It appeared that addition of greater than $0.02 \%$ linoleic acid exerted an inhibitory effect on CLA production in that less was produced in the presence of $0.05 \%$ than in $0.02 \%$ linoleic acid, which was in agreement with the studies of the antimicrobial effect of free linoleic acid on propionic acid bacteria reported by Boyaval et al. (1995) and Jiang et al. (1998). Table 1 shows the production (amounts for each were corrected for background levels in uninoculated broth) of the individual isomers c9t11, t10c12, t9t11, and total CLA in MRS broth supplemented with $0.02 \%$ linoleic acid after $24 \mathrm{~h}$ for the four different cultures of lactobacilli studied. The highest amount of c9t11, t10c12, and t9t11 was produced by $L$. acidophilus $\mathrm{L} 1$ with values of 115.1 , 13.23 , and $7.3 \mu \mathrm{g} / \mathrm{ml}$, respectively, and $131.63 \mu \mathrm{g} / \mathrm{ml}$ for total CLA. The lowest amounts were produced by $L$. acidophilus $\mathrm{O} 16$ with values for c9t11, t10c12, and t9t11 of 54.77, 5.7, and $0.39 \mu \mathrm{g} / \mathrm{ml}$, respectively, and $60.86 \mu \mathrm{g} / \mathrm{ml}$ for the total CLA. A similar pattern of

Table 2. Production of individual isomers and total conjugated linoleic acid (CLA) by Lactobacillus acidophilus and Lactobacillus casei ssp. casei in skim milk supplemented with $0.02 \%$ of linoleic acid after $24 \mathrm{~h}$ of incubation at $37^{\circ} \mathrm{C}$.

\begin{tabular}{|c|c|c|c|c|c|c|}
\hline \multirow[b]{2}{*}{ Culture } & \multirow[b]{2}{*}{$\mathrm{pH}$} & \multirow[b]{2}{*}{$\log _{10} \mathrm{cfu} / \mathrm{ml}^{2}$} & \multicolumn{4}{|c|}{ Concentration $\mu \mathrm{g} / \mathrm{ml}^{1}$} \\
\hline & & & C9t11 & $\mathrm{t} 10 \mathrm{c} 12$ & $\mathrm{t} 9 \mathrm{t} 11$ & Total CLA \\
\hline L. acidophilus $\mathrm{L} 1$ & 5.19 & $7.89 \pm 0.44$ & $100.33 \pm 3.22$ & $9.97 \pm 0.49$ & $6.23 \pm 0.56$ & $116.53 \pm 3.98^{\mathrm{a}}$ \\
\hline L. acidophilus $\mathrm{O} 16$ & 5.89 & $8.35 \pm 0.08$ & $45.30 \pm 4.20$ & $7.83 \pm 0.42$ & $1.02 \pm 0.40$ & $54.31 \pm 4.13^{\mathrm{b}}$ \\
\hline L. casei E5 & 5.87 & $8.24 \pm 0.02$ & $85.03 \pm 4.72$ & $11.97 \pm 0.15$ & $2.90 \pm 0.17$ & $99.63 \pm 4.48^{\mathrm{c}}$ \\
\hline L. casei $\mathrm{E} 10$ & 6.23 & $7.69 \pm 0.06$ & $61.00 \pm 3.06$ & $8.46 \pm 0.57$ & $1.90 \pm 0.50$ & $71.36 \pm 2.75^{\mathrm{d}}$ \\
\hline
\end{tabular}



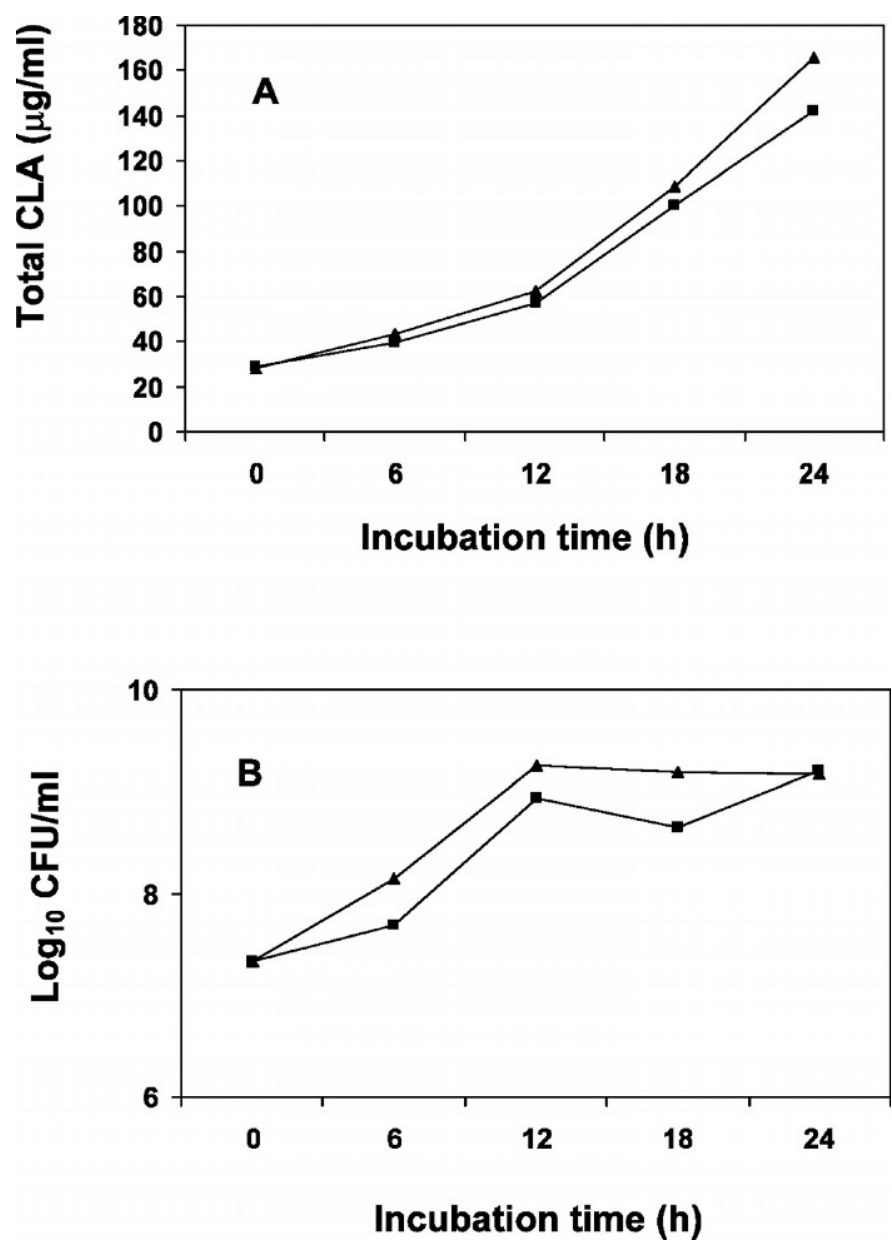

Figure 2. Production of total conjugated linoleic acid (CLA) by Lactobacillus acidophilus L1 (A) and Lactobacillus casei sp. casei E5 (ם) (A) and viable cell count (B) in MRS broth supplemented with $0.02 \%$ linoleic acid after $0,6,12,18$ and $24 \mathrm{~h}$ of incubation at $37^{\circ} \mathrm{C}$.

formation of isomers of CLA was found by Jiang et al. (1998) using different cultures of Propionibacterium sp. This author found that the highest production for the isomers (c9t11 plus t9c11) was $246.4 \mu \mathrm{g} / \mathrm{ml}$ when $750 \mu \mathrm{g} /$ $\mathrm{ml}$ free linoleic acid was added to the media. Lin et al. (1999) found that a culture of $L$. acidophilus produced $105.5 \mu \mathrm{g} / \mathrm{ml}$ of c9t11 in sterilized skim milk supplemented with $1000 \mu \mathrm{g} / \mathrm{ml}$ of free linoleic acid after $24 \mathrm{~h}$ of incubation at $37^{\circ} \mathrm{C}$.

To determine the stage of growth at which the CLA was produced, we analyzed samples of MRS broth containing $0.02 \%$ linoleic acid inoculated with cultures $L$. acidophilus L1 and L. casei E5 after 0, 6, 12, 18, and $24 \mathrm{~h}$ of incubation at $37^{\circ} \mathrm{C}$ (Figure 2). Both cultures exhibited increases in CLA beginning at $6 \mathrm{~h}$. The CLA production increased with each increment of incubation time throughout the $24 \mathrm{~h}$. Growth of both cultures was similar during the 24-h incubation time (Figure 2). Most
CLA was formed after the cultures reached the stationary phase. These results are similar to those found by Lin et al. (1999) when they studied the production of CLA and growth of lactic cultures in skim milk supplemented with free linoleic acid.

The production of CLA by the four cultures of lactobacilli also was measured in skim milk (SM) supplemented with $0.02 \%$ linoleic acid. The variations among the cultures with respect to concentrations of the different isomers (c9t11, t10c12, and t9t11) produced in SM (Table 2) were similar to those formed in MRS broth. In skim milk $L$. acidophilus L1 again produced more CLA than the other cultures $(116.53 \mu \mathrm{g} / \mathrm{ml})$, and $L$. acidophilus $\mathrm{O} 16$ produced the lowest amount (54.31 $\mu \mathrm{g} /$ $\mathrm{ml})$. The apparent differences in the amounts of CLA produced in MRS and skim milk supplemented with the same concentration of free linoleic acid could be due to the different amounts of growth and/or $\mathrm{pH}$ values observed in both media.

In previous studies (Jiang et al., 1998; Lin, 2000; Ogawa et al., 2001; Kishino et al., 2002) on CLA production by starter culture bacteria, the preparation of samples for analyses did not involve removal of the bacterial cells. Thus, there was no evidence presented showing that the CLA was not all contained in the bacterial cells. On the contrary, in our study, we removed the cells and assayed only the free CLA in the spent growth media. While this may not provide data for the total amounts produced (i.e., to include any associated with cells), it may be more important with respect to CLA in the products that would be available for absorption from the digestive tract when the product is consumed. Any CLA incorporated in the cells of the starter cultures may not be readily available in the digestive tract.

\section{ACKNOWLEDGMENTS}

L. Alonso thanks the Ministry of Education of Spain for their support during his time in the Food and Agricultural Product Research and Technology Center at Oklahoma State University.

\section{REFERENCES}

Alonso, L., M. J. Fraga, and M. Juarez. 2000. Determination of trans fatty acids and fatty profiles in margarines marketed in Spain. J. Am. Oil Chem. Soc. 77:131-136.

Boyaval, P., C. Corre, C. Dupuis, and E. Roussel. 1995. Effects of free fatty acids on propionic acid bacteria. Lait 75:17-29.

Brashears, M. M., S. E. Gilliland, and L. M. Buck. 1998. Bile salt deconjugation and cholesterol removal from media by Lactobacillus casei. J. Dairy Sci. 81:2103-2110.

Buck, L. M. and S. E. Gilliland. 1994. Comparisons of freshly isolated strains of Lactobacillus acidophilus of human intestinal origin for ability to assimilate cholesterol during growth. J. Dairy Sci. 77:2925-2933.

Chin, S. F., W. Liu, J. M. Stokson, Y. L. Ha, and M. W. Pariza. 1992. Dietary sources of conjugated linoleic dienoic isomers of linoleic 
acid, a newly recognized class of anticarcinogens. J. Food Comp. Anal. 5:185-197.

Christie, W. W., G. Dobson, and F. D. Gunstone. (1997). Isomers in commercial samples of conjugated linoleic acid. Lipids 32:1231-1232.

Cook, M. E., C. C. Miller, Y. Park, and M. W. Pariza. 1993. Inmune modulation by altered nutrient metabolism: nutritional control of inmune-induced growth depression. Poult. Sci. 72:1301-1305.

Fritsche, J., and H. Steinhart. 1998. Amounts of conjugated linoleic acid (CLA) in German foods and evaluation of dairy intake. Z. Lebensm. Unters Fordsch. 206:77-82.

Ha, Y. L., N. K. Grimm, and M. W. Pariza. 1987. Anticarcinogens from fried ground beef: heat-altered derivatives of linoleic acid. Carcinogenesis 8:1881-1887.

Ha, Y. L., N. K. Grimm, and M. W. Pariza. 1989. Newly recognized anticarcinogenic fatty acids: identification and quantification in natural and processed cheeses. J. Agric. Food Chem. 37:75-81.

Ha, Y. L., J. Storkson, and M. W. Pariza. 1990. Inhibition of benzo (a) pyrene-induced mouse forestomach neoplasia by conjugated dienoic derivatives of linoleic acid. Cancer Res. 50:1097-1101.

Ip, C., S. F. Chin, J. A. Scimeca, and M. W. Pariza. 1991. Mammary cancer prevention by conjugated dienoic derivatives of linoleic acid. Cancer Res. 51:6118-6124.

Ip, C., M. Singh, H. J. Thompson, and J. A. Scimeca. 1994. Conjugated linoleic acid suppresses mammary carcinogenesis and proliferative activity of the mammary gland in the rat. Cancer Res. 54:1212-1215.

Jiang, J., L. Bjoerck, R. Fonden, and M. Emanuelson. 1996. Occurrence of conjugated cis-9, trans-11-octadecadienoic acid in bovine milk; effects of feed and dietary regimen. J. Dairy Sci. 79:438-445.

Jiang, J., L. Bjorck, and R. Fonden. 1998. Production of conjugated linoleic acid by dairy starter cultures. J. Appl. Microbiol. 85:95-102.

Kelly, M. L., J. R. Berry, D. A. Dwyer, J. M. Griinari, P. Y. Chouinard, M. E. Van Amburgh, and D. E. Bauman. 1998. Dietary fatty acid sources affect conjugated linoleic acid concentrations in milk from lactating dairy cows. J. Nutr. 128:881-885.

Kim, Y. J., and R. H. Liu. 2000. Selective increase in conjugated linoleic acid in milk fat by crystallization. J. Food Sci. 5:792-795.
Kishino, S., J. Ogawa, Y. Omura, K. Matsumura, and S. Shimizu. 2002. Conjugated linoleic acid production from linoleic acid by lactic acid bacteria. J. Am. Oil Chem. Soc. 79:159-163.

Koritala, S., and W. K. Rohwedder. 1972. Formation of an artifact during methylation of conjugated fatty acids. Lipids 7:274-278.

Lee, K. N., D. Kritchevsky, and M. W. Pariza. 1994. Conjugated linoleic acid and atherosclerosis in rabbits. Atherosclerosis 108:19-25.

Lawless, F., J. J. Murphy, D. Harrington, R. Devery, and C. Stanton. 1998. Elevation of conjugated cis-9, trans-11-octadecadienoic acid in bovine milk because of dietary supplementation. J. Dairy Sci. 81:3259-3267.

Lin, T. Y. 2000. Conjugated linoleic acid concentration as affected by lactic cultures and additives. Food Chem. 69:27-31.

Lin, T. Y., C. W. Lin, and C. H. Lee. 1999. Conjugated linoleic acid concentration as affected by lactic cultures and added linoleic. Food Chem. 67:1-5.

Ogawa, J., K. Matsumura, S. Kishino, Y. Omura, and S. Shimizu. 2001. Conjugated linoleic acid accumulation via 10-hydroxy-12octadecaenoic acid during microaerobic transformation of linoleic acid by Lactobacillus acidophilus. Appl. Environ. Microbiol. 67:1246-1252.

Pariza, M. W., Y. Park, M. Cook, K. Albrigh, and W. Liu. 1996. Conjugated linoleic acid (CLA) reduces body fat. FASEB J. 10:3227.

$\mathrm{SAS}^{\circledR}$ User's Guide: Statistics, Version 6.12. Edition. 1995. SAS Inst., Inc., Cary, NC.

Shanta, N. C., E. A. Decker, and Z. Ustunol. 1992. Conjugated linoleic acid concentration in processed cheese. J. Am. Oil Chem. Soc. 69:425-428.

Stanton, C., F. Lawless, G. Kjellmer, D. Harrington, R. Devery, J. C. Connoly, and J. J. Murphy. 1997. Dietary influences on bovine milk cis-9, trans-11-conjugated linoleic acid content. J. Food Sci. 62:1083-1086.

Yurawecz, M. P., K. G. Kramer, and Y. Ku. 1996. Methylation procedures for conjugated linoleic acid. Pages 64-82 in Advances in Conjugated Linoleic acid Research. Vol. 1. M. P. Yurawecz, M. M. Mosoba, J. K. G. Kramer, M. W. Pariza, and G. T. Nelson, ed. AOCS Press, Champaign, IL.

Yurawecz. 1997. Evaluating acid and base catalysts in the methylation of milk and rumen fatty acids with special emphasis on conjugated dienes and total. Lipids 32:1219-1228. 